\title{
Surgical Resection of a Rapidly Growing Giant Pericardial Cyst: A Case Report
}

\author{
Masanori Yokoba $^{1 *}$, Chiaki Kusanagi ${ }^{2}$, Naomi Kuroudu ${ }^{3}$, Yukitoshi Satoh ${ }^{3}$, Noriyuki Masuda ${ }^{1}$, \\ Masato Katagiri ${ }^{1}$ \\ ${ }^{1}$ Department of Pulmonary Medicine, Kitasato University, Kitasato, Japan; ${ }^{2}$ Department of Clinical Laboratories, Kitasato University, \\ Kitasato, Japan; ${ }^{3}$ Department of Thoracic Surgery, Kitasato University Hospital, Kitasato, Japan. \\ Email: *myoko@kitasato-u.ac.jp
}

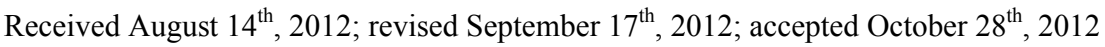

\begin{abstract}
We report here a case of a patient who underwent surgical resection of a giant pericardial cyst that was growing rapidly, causing anterior chest pain. An asymptomatic 56-year-old woman underwent a complete medical checkup in a healthcare center. Her chest X-ray showed an unusually large bulge on the left cardiac border, and she was referred to our hospital. The chest X-ray taken 2 years ago in another hospital showed similar bulge on the same left cardiac border, but it was noticeably smaller. Chest CT revealed a $9.5 \times 4.5 \mathrm{~cm}$ pericardial cyst within the anterolateral aspect of the left cardiac border. The CT number of the mass was approximately $15-20 \mathrm{HU}$. The mass also showed slight hyperintensity on T1-weighted MR images and hyperintensity on T2-weighted MR images. Four weeks later, she experienced anterior chest pain for the first time, and the chest X-ray and CT showed an increase in the size of the pericardial cyst. The CT number of the mass increased to approximately $30-40 \mathrm{HU}$. The cyst was successfully removed by video-assisted thoracic surgery. The pericardial cyst was diagnosed as benign according to the results of histopathology. We conclude that the rapid growth of the pericardial cyst was caused by intracystic hemorrhage that originated from vascularized connective tissue in the cyst wall.
\end{abstract}

Keywords: Pericardial Cyst; Intracystic Hemorrhage; Video-Assisted Thoracic Surgery; Mediastinal Mass

\section{Introduction}

Pericardial cysts occur in 1 out of every 100,000 persons $[1,2]$ and represent $6 \%-7 \%$ of all mediastinal masses [3]. Research indicates that they are caused by an incomplete coalescence of fetal lacunae during the development of the pericardium [4]. Most patients are asymptomatic, and these cysts are usually detected as incidental findings on chest X-rays [5]. Therefore, the natural history of pericardial cysts is unknown [6]. Most cases are asymptomatic and stable and only require follow-up. In contrast, surgical removal of cysts is required when they enlarge and cause symptoms such as chest discomfort or tightness, particularly in a supine position, and aching or pain caused by compression of the coronary arteries or cyst rotation.

\section{Case Report}

An asymptomatic 56-year-old woman underwent a complete medical checkup in a healthcare center. She was a

"Corresponding author. beautician and gave a history of smoking a pack of cigarettes daily for 14 years; she had ceased smoking at the time of admission. Her mother died from liver cancer and the patient was an asymptomatic antigen-positive carrier of hepatitis B virus. Cardiovascular examination revealed a regular heart rate and rhythm with no murmur. Lung examination detected no significant pulmonary rales. All other findings were unremarkable as follows: white blood cell count, $5.1 \times 10^{3} / \mu \mathrm{L}$; red blood cell count, $4.57 \times 10^{6} / \mu \mathrm{L}$; hemoglobin level, $13.4 \mathrm{~g} / \mathrm{dL}$; platelet count, $13.9 \times 10^{4} / \mu \mathrm{L}$; and C-reactive protein level, 0.03 $\mathrm{mg} / \mathrm{dL}$ (Table 1). Her chest X-ray showed an unusually large bulge on the left cardiac border (Figure 1(A)). On the lateral projection, it appeared as an area of increased density overlying the upper cardiac silhouette (Figure 1(B)). She was referred to our hospital for further investigations. Her chest X-ray taken 2 years ago in another hospital showed a similar abnormality, but it was noticeably smaller than the current cyst (Figure 2). Computed tomography of the chest revealed a $9.5 \times 4.5 \mathrm{~cm}$ pericardial cyst of the anterolateral aspect of the left cardiac border (Figure 3). The inner constitution was uniform, 
Table 1. Laboratory findings.

\begin{tabular}{|c|c|c|c|c|c|}
\hline \multicolumn{2}{|l|}{ Hematology } & \multicolumn{2}{|l|}{ Blood Chemistry } & \multicolumn{2}{|l|}{ Serology } \\
\hline WBC & $5.1 \times 10^{3} / \mu \mathrm{L}$ & T.P. & $7.0 \mathrm{~g} / \mathrm{dL}$ & CRP & $0.03 \mathrm{mg} / \mathrm{dL}$ \\
\hline Neutrophils & $58.6 \%$ & $\mathrm{Alb}$ & $4.0 \mathrm{~g} / \mathrm{dL}$ & & \\
\hline Eosinophil & $4.0 \%$ & T.Bil. & $0.6 \mathrm{~g} / \mathrm{dL}$ & $\underline{\text { HBsAg }}$ & $>2000$ C.O.I \\
\hline Lymphocytes & $23.6 \%$ & GOT & $27 \mathrm{IU} / \mathrm{L}$ & $\mathrm{HBsAb}$ & $0 \mathrm{mIU} / \mathrm{mL}$ \\
\hline Monocytes & $4.0 \%$ & GPT & $22 \mathrm{IU} / \mathrm{L}$ & HCVAb & 0.1 C.O.I \\
\hline Basophils & $0.8 \%$ & ALP & $200 \mathrm{IU} / \mathrm{L}$ & & \\
\hline Erythrocytes & $4.57 \times 10^{6} / \mu \mathrm{L}$ & $\gamma$-GTP & $13 \mathrm{IU} / \mathrm{L}$ & CEA & $1.2 \mathrm{ng} / \mathrm{mL}$ \\
\hline Hemoglobin & $13.4 \mathrm{~g} / \mathrm{dL}$ & LDH & $540 \mathrm{IU} / \mathrm{L}$ & AFP & $4 \mathrm{ng} / \mathrm{mL}$ \\
\hline Hematocrit & $39.9 \%$ & AMY & $74 \mathrm{IU} / \mathrm{L}$ & CA19-9 & $9 \mathrm{IU} / \mathrm{mL}$ \\
\hline \multirow[t]{8}{*}{ Platelet count } & $13.9 \times 10^{4} / \mu \mathrm{L}$ & BUN & $15.4 \mathrm{mg} / \mathrm{dL}$ & CA125 & $12 \mathrm{IU} / \mathrm{mL}$ \\
\hline & & Creat. & $0.70 \mathrm{mg} / \mathrm{dL}$ & & \\
\hline & & FBS & $100 \mathrm{mg} / \mathrm{dL}$ & & \\
\hline & & HbA1c (NGSP) & $5.3 \%$ & & \\
\hline & & $\mathrm{Na}$ & $141 \mathrm{mEq} / \mathrm{L}$ & & \\
\hline & & K & $4.0 \mathrm{mEq} / \mathrm{L}$ & & \\
\hline & & $\mathrm{Cl}$ & $108 \mathrm{mEq} / \mathrm{L}$ & & \\
\hline & & $\mathrm{Ca}$ & $8.1 \mathrm{mEq} / \mathrm{L}$ & & \\
\hline
\end{tabular}

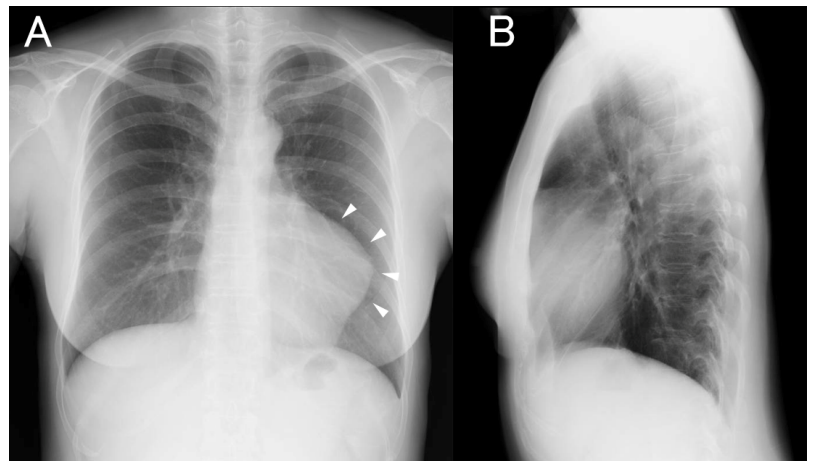

Figure 1. Frontal view of the chest $X$-ray showing a large bulge on the left cardiac border ((A), arrowheads). The lateral view revealed an increased density overlaying the upper cardiac silhouette (B).

the mass was not enhanced with contrast, and its CT number was approximately $15-20$ Hounsfield units (HU). There was no continuity between the coronary arteries and the pericardial cyst. The boundary of the pericardium and pericardial cyst was ambiguous at the level of the left atrium and the left ventricle, and it was considered to be the binding site of the pericardial cyst and pericardium. An MRI of the chest showed a well-defined lesion with homogenous, slight hyperintensity on T1-weighted imaging (Figure 4(A)) and hyperintensity on T2-weighted imaging (Figure 4(B)). These views, the high CT number, and slightly high intensity on T1-weighted imaging are generally observed in cases of bleeding.

Echocardiography was also performed (Figure 5). A large extrinsic echo-free space was adjoined to the left atrium and left ventricle. A clear alteration of the size of

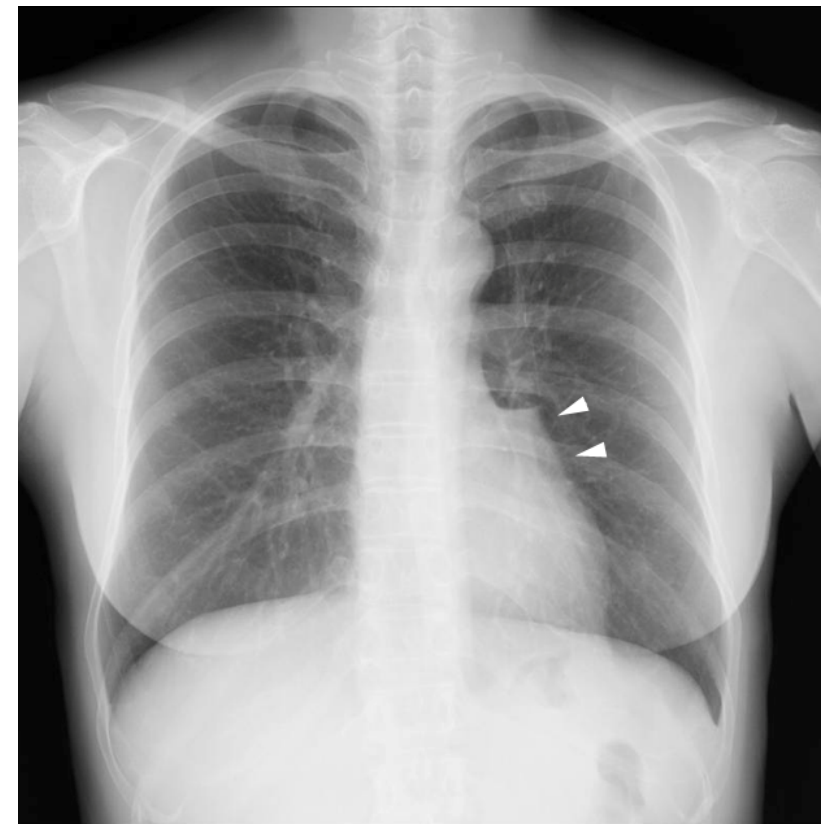

Figure 2. Chest X-ray taken 2 years earlier showing a similar but smaller bulge on the left cardiac border (arrow heads).

the echo-free space was not demonstrated during the systolic and diastolic phases. In color Doppler ultrasonography, a blood flow signal was not observed in the cystic area. Left ventricular wall motion was normal and pericardial effusion was not apparent. On the basis of the above findings, the patient was diagnosed with a pericardial cyst.

Four weeks later, she experienced anterior chest pain 


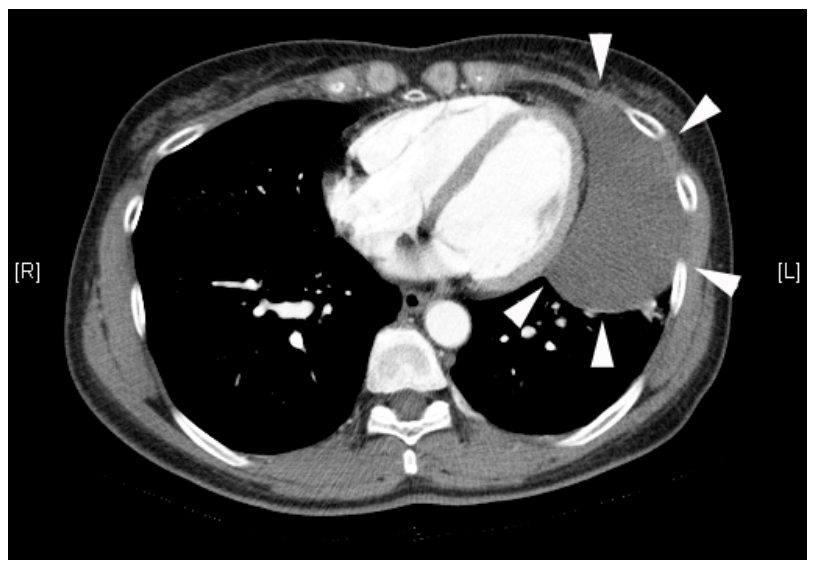

Figure 3. Contrast-enhanced computed tomography demonstrating a $9.5 \times 4.5 \mathrm{~cm}$ pericardial cyst of the anterolateral aspect of the left cardiac border (arrowheads).

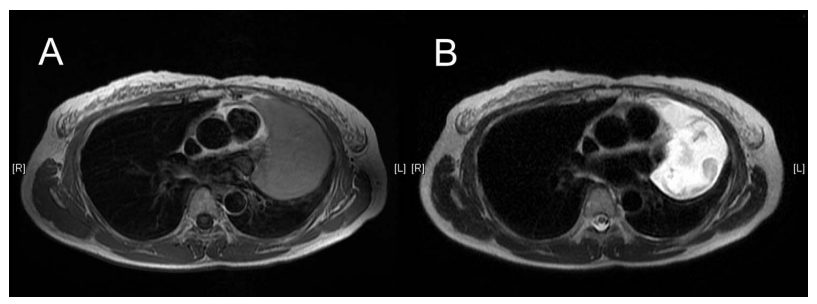

Figure 4. MRI showed a well-defined lesion with homogenous, slight hyperintensity on T1-weighted imaging (A) and hyperintensity on T2-weighted imaging (B).

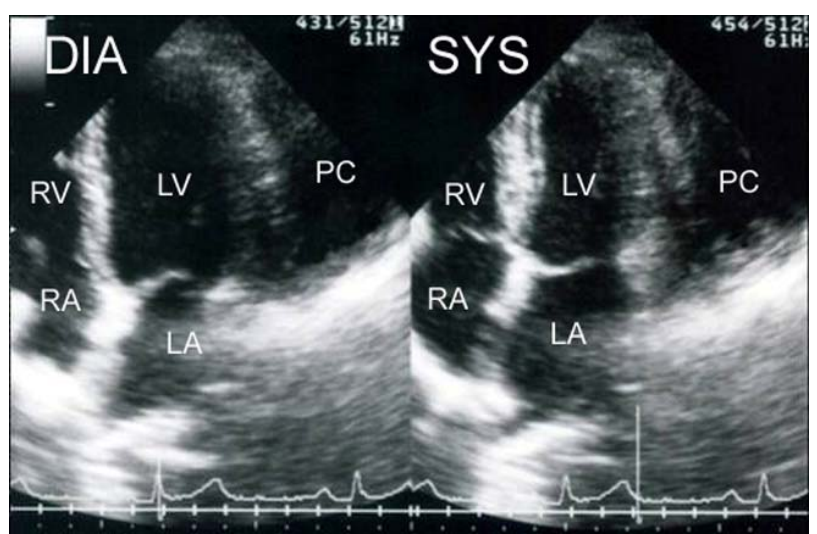

Figure 5. Echocardiogram, apical 4-chamber view, showing a large extrinsic mass (PC) adjoined to the left atrium and the left ventricle. The size of echo-free space (PC) did not change synchronization with the motion of the heart. DIA: diastolic phase; SYS: systolic phase; LA: left atrium; LV: left ventricle; RA: right atrium; RV: right ventricle; $P C$ : pericardial cyst.

for the first time. Chest X-ray, chest CT, and echocardiography were performed, and they revealed that the pericardial cyst had enlarged (Figures 6(A) and (B)). The CT number increased to approximately 30 - $40 \mathrm{HU}$. Moreover, her red blood cell count and hemoglobin level were decreased as compared with the previous blood examination (white blood cells count, $5.7 \times 10^{3} / \mu \mathrm{L}$; red blood cell count, $4.15 \times 10^{6} / \mu \mathrm{L}$; hemoglobin level, 12.5 $\mathrm{g} / \mathrm{dL}$; platelet count, $18.6 \times 10^{4} / \mu \mathrm{L}$; and C-reactive protein level, $1.47 \mathrm{mg} / \mathrm{dL}$ ).

Surgical resection was planned, and the cyst was successfully removed by video-assisted thoracic surgery. The size of resected cyst was $10.5 \times 7.5 \mathrm{~cm}$ (Figure 7). It was unilocular and filled with a brown viscoid fluid. Histopathological examination revealed that a part of the cyst wall was lined by a single layer of flat or cuboidal mesothelial cells. Almost all portions of the cyst wall consisted of vascularized connective tissue and hemosiderin-laden macrophages, and exfoliated mesothelial cells were observed (Figures 8(A) and (B)). No evidence of malignancy was detected.

\section{Discussion}

Pericardial cysts are often discovered as incidental findings on chest X-ray or CT. They are located typically at the cardiophrenic angles (at right and left sides in $51 \%$ $70 \%[3,7]$ and $10 \%-40 \%$ of patients [8], respectively)

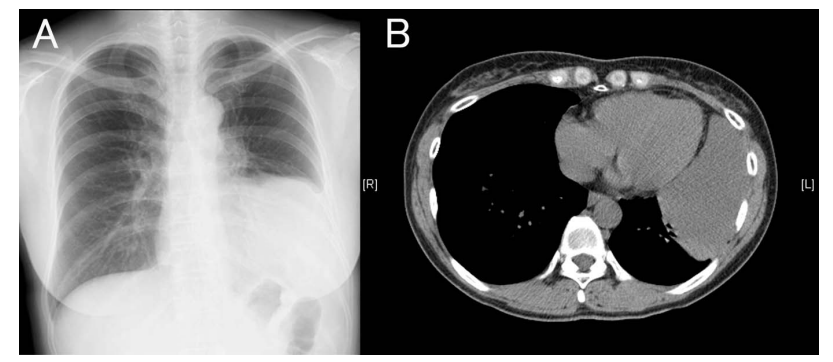

Figure 6. Chest X-ray (A) and CT imaging (B) acquired 4 weeks after the initial examination revealing that the pericardial cyst became markedly enlarged.

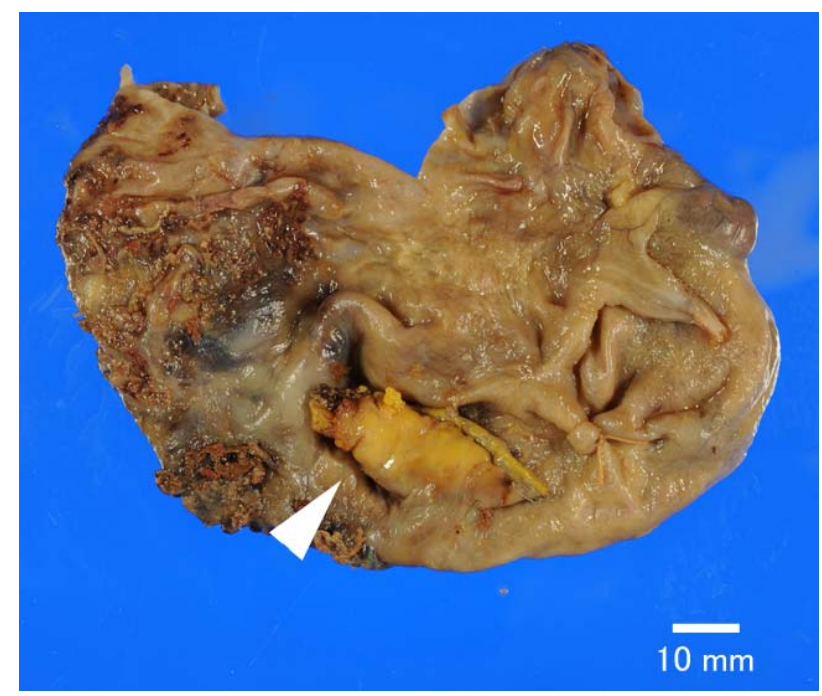

Figure 7. Resected tissue showing the unilocular cyst and boundaries of the pericardium and the pericardial cyst (arrowhead). 

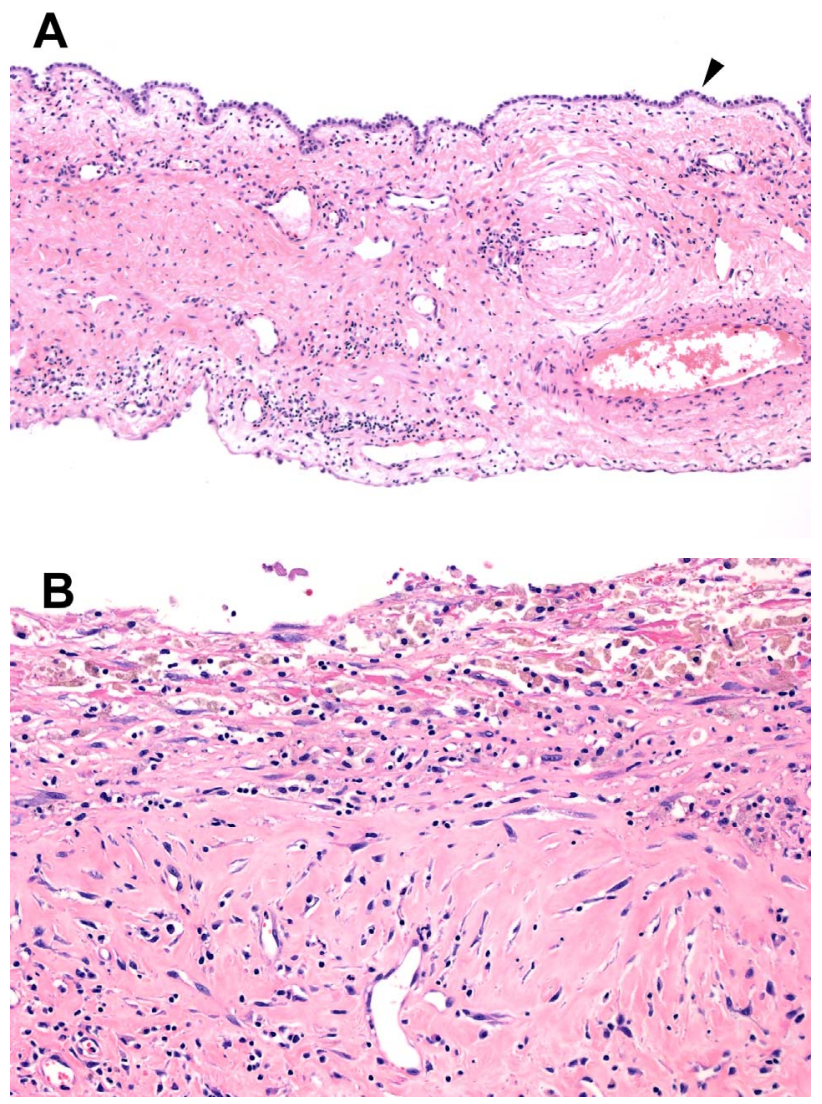

Figure 8. A part of the cyst wall consists of a single layer of flat or cuboidal mesothelial cells supported by loose connective tissue [(A) hematoxylin and eosin (H \& E) stain $\times 100$, arrowhead]. Almost all portions of the cyst wall consisted of vascularized connective tissue and hemosiderin-laden macrophages, and exfoliated mesothelial cells were observed. [(B) H \& E stain $\times 200]$.

and rarely in other mediastinal locations not adjacent to the diaphragm (the hilum and the superior mediastinum at the level of the aortic arch [3,9]). In the present case, the cyst was found on the left cardiophrenic angle, and the binding site of the pericardial cyst and the pericardium was at the demarcation level of the left atrium and the left ventricle. Pericardial cysts usually are less than $5 \mathrm{~cm}$ in diameter $[4,10]$. Pericardial cysts with a diameter $>10 \mathrm{~cm}$ are referred to as "giant pericardial cysts" [6].

A characteristic CT scan finding of a typical pericardial cyst is the presence of a homogeneous mass with the similar attenuation as water that is not enhanced with contrast. MRI examination also shows the cyst contains serous fluid that produces low signal intensity on T1weighted MRI and high signal intensity on T2-weighted MRI. In the present case, the CT number of the mass was higher than that of water $(15-20 \mathrm{HU})$. We also found that the signal intensity was slightly high on T1-weighted MRI and high on T2-weighted MRI. These views are generally seen in cases of hemorrhage. After this exami- nation, the patient's pericardial cyst enlarged and was accompanied by obvious anterior chest pain for a short time, and the CT number was higher $(30-40 \mathrm{HU})$ than observed previously.

Pericardial cysts usually follow a benign course in the majority of cases; however, symptomatic or large pericardial cysts require surgical resection, video-assisted thoracic surgery, or percutaneous aspiration with ethanol sclerosis [11]. In the present case, the cyst was removed by video-assisted thoracic surgery. Histopathological examination showed evidence of intracystic hemorrhage. CT numbers, MRI intensity, histopathological examination of the lesion as well as complete blood cell counts and serum chemistry provide insights into why the cyst grew so rapidly. Thus, we interpret these results to mean that the fluid in the cyst detected during the first examination already included sparse areas of blood. The subsequent rapid growth that formed a giant pericardial cyst accompanied by anterior chest pain was caused by intracystic massive bleeding from vascularized connective tissue in the cyst wall.

Pericardial cysts occasionally cause complications including erosion into adjacent structures such as the right ventricular wall [12] or the superior vena cava [13], cyst rupture [14], cardiac tamponade [15,16], atrial fibrillation [17], obstruction of the right mainstem bronchus [18], and sudden death [19]. We conclude that our patient may have been at risk of pericardial cyst rupture when she felt chest pain. Therefore, careful observation is necessary whenever a patient with pericardial cyst is being followed up.

\section{Conclusion}

We report here a case of a rapidly growing, giant pericardial cyst. The results of our examinations led us to conclude that the rapid growth resulted from a large intracystic hemorrhage originating from vascularized connective tissue in the cyst wall. Therefore, we advise pulmonologists to be aware that pericardial cysts can enlarge rapidly and cause potential complications.

\section{REFERENCES}

[1] J. K. Hynes, A. J. Tajik, M. J. Osborn, T. A. Orszulak and J. B. Seward, "Two-Dimensional Echocardiographic Diagnosis of Pericardial Cyst," Mayo Clin Proceedings, Vol. 58, No. 1, 1983, pp. 60-63.

[2] D. C. Jarzabkowski and D. B. Braunstein, "Pericardial Cyst: An Incidental Finding," Journal of American Osteopathic Association, Vol. 98, No. 8, 1998, pp. 445-446.

[3] A. Gurlek, Z. Dagalp and U. Ozyurda, "A Case of Multiple Pericardial Hydatid Cysts," International Journal of Cardiology, Vol. 36, No. 3, 1992, pp. 366-368. doi:10.1016/0167-5273(92)90310-Y

[4] C. M. Satur, M. K. Hsin and J. E. Dussek, "Giant Peri- 
cardial Cysts," Annals of Thoracic Surgery, Vol. 61, No. 1, 1996, pp. 208-210. doi:10.1016/0003-4975(95)00720-2

[5] B. Maisch, P. M. Seferovic, A. D. Ristic, R. Erbel, R. Rienmuller, Y. Adler, W. Z. Tomkowski, G. Thiene and M. H. Yacoub, "Guidelines on the Diagnosis and Management of Pericardial Diseases Executive Summary; The Task Force on the Diagnosis and Management of Pericardial Diseases of the European Society of Cardiology," European Heart Journal, Vol. 25, No. 7, 2004, pp. 587610. doi:10.1016/j.ehj.2004.02.002

[6] R. Matono, F. Shoji, T. Yano and Y. Maehara, "Surgical Resection of a Giant Pericardial Cyst Showing a Rapidly Growing Feature," Interactive Cardiovascular and Thoracic Surgery, Vol. 10, No. 6, 2010, pp. 1056-1058. doi:10.1510/icvts.2009.231456

[7] A. C. Borges, K. Gellert, M. Dietel, G. Baumann and C. Witt, "Acute Right-Sided Heart Failure Due to Hemorrhage into a Pericardial Cyst," The Annals of Thoracic Surgery, Vol. 63, No. 3, 1997, pp. 845-847. doi:10.1016/S0003-4975(96)01373-2

[8] L. Minutiello, "The Usefulness of Echocardiography in the Differential Diagnosis of a Pericardial Cyst Simulating an Aneurysm of the Left Ventricle," Minerva Cardioangiologica, Vol. 42, No. 6, 1994, pp. 313-319.

[9] J. K. Stoller, C. Shaw and R. A. Matthay, "Enlarging, Atypically Located Pericardial Cyst. Recent Experience and Literature Review," Chest, Vol. 89, No. 3, 1986, pp. 402-406. doi:10.1378/chest.89.3.402

[10] V. J. Nina, N. C. Manzano, V. G. Mendes and N. Salgado Filho, "Giant Pericardial Cyst: Case Report," Revista Brasileira de Cirurgia Cardiovascular, Vol. 22, No. 3, 2007, pp. 349-351. doi:10.1590/S0102-76382007000300013

[11] E. C. Klatte and H. Y. Yune, "Diagnosis and Treatment of Pericardial Cysts," Radiology, Vol. 104, No. 3, 1972, pp. 541-544.
[12] P. S. Chopra, D. J. Duke, J. R. Pellett and P. S. Rahko, "Pericardial Cyst with Partial Erosion of the Right Ventricular Wall," Annals of Thoracic Surgery, Vol. 51, No. 5, 1991, pp. 840-841. doi:10.1016/0003-4975(91)90149-K

[13] P. Mastroroberto, M. Chello, E. Bevacqua and A. R. Marchese, "Pericardial Cyst with Partial Erosion of the Superior Vena Cava. An Unusual Case," Journal of Cardiovascular Surgery, Vol. 37, No. 3, 1996, pp. 323-324.

[14] F. A. Padder, A. R. Conrad, K. J. Manzar, N. Thayapran, E. E. Jonas and I. Freeman, "Echocardiographic Diagnosis of Pericardial Cyst," American Journal of the Medical Sciences, Vol. 313, No. 3, 1997, pp. 191-192. doi:10.1097/00000441-199703000-00012

[15] I. Shiraishi, M. Yamagishi, A. Kawakita, Y. Yamamoto and K. Hamaoka, "Acute Cardiac Tamponade Caused by Massive Hemorrhage from Pericardial Cyst," Circulation, Vol. 101, No. 19, 2000, pp. E196-E197. doi:10.1161/01.CIR.101.19.e196

[16] R. Nijveldt, A. M. Beek, J. M. van Gorp and A. C. van Rossum, "Pericardial Cyst," Lancet, Vol. 365, No. 9475, 2005, p. 1960. doi:10.1016/S0140-6736(05)66664-0

[17] S. C. Vlay and A. R. Hartman, "Mechanical Treatment of Atrial Fibrillation: Removal of Pericardial Cyst by Thoracoscopy," American Heart Journal, Vol. 129, No. 3, 1995, pp. 616-618. doi:10.1016/0002-8703(95)90293-7

[18] W. C. Davis, J. D. German and N. J. Johnson, "Pericardial Diverticulum Causing Pulmonary Obstruction," Archives of Surgery, Vol. 82, 1961, pp. 285-289.

[19] C. S. Fredman, S. R. Parsons, T. I. Aquino and W. P. Hamilton, "Sudden Death after a Stress Test in a Patient with a Large Pericardial Cyst," American Heart Journal, Vol. 127, No. 4, 1994, pp. 946-950. 